\title{
PENGARUH ORGANIZATIONAL CITIZENSHIP BEHAVIOR (OCB) TERHADAP KINERJA KARYAWAN PADA PT. INTI KHARISMA MANDIRI RIAU PEKANBARU
}

\author{
Sahwitri Triandani, SE, M.Si \\ (Dosen Fekonsos UIN Suska Riau)
}

\begin{abstract}
Abstrak
PT. Inti Kharisma Mandiri Riau Pekanbaru adalah salah satu perusahaan swasta yang bergerak di bidang percetakan dan penerbitan surat kabar dengan nama "Harian Umum Haluan Riau". Beberapa permasalahan yang terjadi di PT. Inti Kharisma Mandiri Riau Pekanbaru berkaitan dengan perilaku Organizational Citizenship Behavior (OCB) yang berpengaruh terhadap kinerja karyawan. Teori yang digunakan dalam penelitian ini adalah teori-teori Manajemen Sumber Daya Manusia dan Perilaku Organisasi terutama yang berkaitan dengan OCB dan kinerja. Metode yang digunakan dalam penelitian ini adalah pendekatan survey, jenis penelitian adalah deksriptif kuantitatif, dan sifat penelitian adalah penjelasan (explanatory). Metode pengumpulan data dilakukan dengan wawancara dan daftar pertanyaan. Metode analisis data yang digunakan adalah regresi linier berganda. Populasi adalah seluruh karyawan bidang redaksi PT. Inti Kharisma Mandiri Riau yang berjumlah 100 orang. Penentuan sampel dalam penelitian ini menggunakan rumus Slovin dengan menggunakan taraf kepercayaan sebesar 90 persen dan jumlah sampel sebanyak 50 orang karyawan. Kesimpulan penelitian ini adalah: 1) Secara serempak variabel OCB yang terdiri dari kepatuhan (obedience), loyalitas (loyality) dan partisipasi berpengaruh sangat signifikan terhadap kinerja karyawan, serta 2) Secara parsial loyalitas berpengaruh sangat signifikan terhadap kinerja karyawan PT. Inti Kharisma Mandiri Riau Pekanbaru.
\end{abstract}

Kata kunci: Organizational Citizenship Behavior (OCB), kepatuhan (obedience), loyalitas, partisipasi.

\section{Pendahuluan}

Kesuksesan dan keberhasilan suatu organisasi atau perusahaan dapat ditentukan oleh banyak hal, salah satu hal terpenting yang dapat menentukannya adalah sumber daya manusia (SDM) yang dimiliki. Perusahaan yang dapat mengelola dan mengoptimalkan SDM secara berkualitas, dipastikan akan meraih kesuksesan dan produktivitas yang tinggi. Oleh karena itu sumber daya manusia (SDM) merupakan aset yang sangat penting dan berharga bagi perusahaan. Salah satu perilaku yang dapat meningkatkan produktivitas perusahaan adalah perilaku yang tentu saja mengarah ke hal-hal positif atau yang dikenal sebagai Organizational citizenship behavior (OCB).
Organizational citizenship behavior (OCB) merupakan kontribusi individu yang mendalam melebihi tuntutan peran di tempat kerja dan direward oleh pemberian kinerja tugas. OCB ini melibatkan beberapa perilaku meliputi perilaku menolong orang lain, menjadi volunteer untuk tugas-tugas ekstra, patuh terhadap aturan dan prosedur di tempat kerja. Perilaku ini menggambarkan nilai tambah karyawan dan merupakan salah satu bentuk perilaku prososial yaitu perilaku social yang positif, konstruktif dan bermakna membantu. Tugas-tugas pimpinan akan menjadi lebih ringan jika terdapat karyawankaryawan dengan ocb tinggi sehingga konsukuensinya akan meningkatkan kinerja pribadi dan kinerja organisasi. 
Perilaku OCB merupakan perilaku yang dilakukan secara sukarela (sekehendak hati) oleh karyawan dengan tanpa meminta imbalan apapun dari perusahaan dan secara langsung dapat meningkatkan efektivitas dan efisiensi di dalam perusahaan. Perilaku ini meliputi 3 elemen utama yaitu, kepatuhan (obedience), loyalitas (loyalty), dan partisipasi. Sejak era reformasi, pemerintah telah memberi kemudahan dalam proses pemberian surat ijin usaha penerbitan, sehingga dalam beberapa tahun terakhir ini banyak surat kabar diterbitkan baik di kotakota maupun di daerah-daerah. Oleh karena itu, persaingan dalam bisnis surat kabar belakangan ini semakin berat dan kompetitif. Hal ini menyebabkan PT. Inti Kharisma Mandiri Riau Pekanbaru dengan produknya yaitu harian umum "Haluan Riau " selalu dituntut untuk lebih produktif dengan mengedepankan mutu serta memahami keinginan masyarakat. PT. Inti Kharisma Mandiri Riau Pekanbaru ini memiliki dua bidang dalam kegiatannya yaitu bidang usaha dan bidang redaksi. Bidang redaksi terdiri dari para jurnalis atau wartawan yang memiliki tugas utama memperoleh berita untuk kemudian diolah menjadi berita yang berisi, bermanfaat dan up to date sehingga layak dibaca oleh masyarakat.

Bidang redaksi dalam pekerjaannya terkadang menemui hambatan dan permasalahan, hambatan dan permasalahan itu berdampak pada kinerja karyawan yang semakin menurun yang terindikasi dari berkurangnya jumlah perolehan berita sehingga tidak lagi sesuai dengan target yang ditetapkan perusahaan. Hal ini dapat dilihat pada tabel di bawah ini.
Target dan Realisasi Perolehan Berita Pada Harian "Haluan Riau"

\begin{tabular}{|c|c|c|}
\hline \multirow{2}{*}{ Tahun } & \multicolumn{2}{|c|}{ Perolehan Berita } \\
\cline { 2 - 3 } & Target & Realisasi \\
\hline 2019 & 5.760 & 5.750 \\
\hline 2011 & 6.480 & 6.215 \\
\hline 2012 & 8.460 & 8.100 \\
\hline 2013 & 8.650 & 7.250 \\
\hline
\end{tabular}

Sumber : PT Inti Kharisma Mandiri Riau (data diolah), 2014

Tabel diatas menggambarkan kondisi bahwa perolehan berita dari tahun ke tahun tidak pernah mencapai target yang diharapkan. Target yang semakin tinggi bila tidak didukung oleh rekan kerja yang bersedia membantu serta pemimpin yang tidak pengertian dan faktor-faktor lain akan berakibat pada menurunnya kinerja individu.

\section{Perumusan Masalah}

1. Apakah OCB yang terdiri dari kepatuhan (obedience), loyalitas (loyality) dan partisipasi mempunyai pengaruh terhadap terhadap kinerja karyawan PT.Inti Kharisma Mandiri Riau Pekanbaru?

2. Apakah OCB yang terdiri dari kepatuhan (obedience), loyalitas (loyality) dan partisipasi mempunyai pengaruh secara simultan terhadap terhadap kinerja karyawan PT.Inti Kharisma Mandiri Riau Pekanbaru?

\section{Tujuan Penelitian}

1. Untuk mengetahui dan mangkaji pengaruh OCB yang terdiri dari kepatuhan (obedience), loyalitas (loyality) dan partisipasi mempunyai pengaruh terhadap terhadap kinerja karyawan PT.Inti Kharisma Mandiri Riau Pekanbaru.

2. Untuk mengetahui dan mengkaji secara simultan OCB yang terdiri dari kepatuhan (obedience), loyalitas (loyality) dan partisipasi terhadap kinerja karyawan PT.Inti Kharisma Mandiri Riau Pekanbaru. 


\section{Kegunaaan Penelitian}

Hasil penelitian ini diharapkan berguna untuk:

1. Pengembangan ilmu manajemen khususnya manajemen sumber daya manusia dan perilaku organisasi.

2. Memberikan informasi tambahan yang berguna untuk mengenal lebih jauh tentang materi OCB yang berkaitan dengan perilaku dan kinerja.

3. Masukan dalam penerapan pelaksanaan OCB dan pengaruhnya terhadap kinerja karyawan PT. Inti Kharisma Mandiri Riau Pekanbaru.

\section{Landasan Teori}

Konsep OCB pertama kali didiskusikan dalam literatur penelitian organisasional pada awal 1980an (Bateman dan Organ, 1983; Smith et al., 1983; dalam Bienstock et al.(2003: 360), Robbins mengemukakan bahwa OCB merupakan perilaku pilihan yang tidak menjadi bagian dari kewajiban kerja formal seorang karyawan, namun mendukung berfungsinya organisasi tersebut secara efektif (2006: 31). Menurut Organ, OCB adalah perilaku individu yang bebas, tidak secara langsung atau eksplisit diakui dalam sistem pemberian penghargaan dan dalam mempromosikan fungsi efektif organisasi. Atau dengan kata lain, OCB adalah perilaku karyawan yang melebihi peran yang diwajibkan, yang tidak secara langsung atau eksplisit diakui oleh sistem reward formal ( Organ, 1988; dalam Bolino, Turnley dan Bloodgood 2002: 505 ). Bebas dalam arti bahwa perilaku tersebut bukan merupakan persyaratan yang harus dilaksanakan dalam peran tertentu atau deskripsi kerja tertentu, atau perilaku yang merupakan pilihan pribadi ( Podsakoff et al. 2000: 513).

OCB juga sering diartikan sebagai perilaku yang melebihi kewajiban formal (ekstra role)yang tidak berhubungan dengan kompensasi langsung. Artinya, seseorang yang memiliki OCB tinggi tidak akan dibayar dalam bentuk uang atau bonus tertentu, namun OCB lebih kepadaperilaku sosial dari masing-masing individu untuk bekerja melebihi apa yang diharapkan, sepertimembantu rekan di saat jam istirahat dengan sukarela adalah salah satu contohnya. Kedudukan OCB sebagai salah satu bentuk perilaku extra-role, telah menarik perhatian dan perdebatan panjang di kalangan praktisi organisasi, peneliti maupun akademisi.

Marshall (1950) dalam Vigoda dan Golembiewski ( 2001: 279) mengemukakan bahwa secara umum citizenship behavior merujuk pada 3 elemen utama yaitu, kepatuhan (obedience), loyalitas (loyalty), dan partisipasi. Kepatuhan dan loyalitas secara alami merupakan definisi citizenship dalam pengertian yang luas, sehingga esensi dari citizenship behavior adalah partisipasi. Dalam partisipasi, perhatian terutama ditujukan pada arena nasional (governance), arena komunal (local lives), dan arena organisasional(tempat kerja). Sedangkan Graham (1991) dalam Bolino, Turnley dan Bloodgood (2002: 508) memberikan konseptualisasi OCB yang berbasis pada filosofi politik dan teori politik modern.

Sedangkan Ariani (2008) dalam penelitiannya menemukan bahwa OCB merupakan perilaku positif di tempat kerja yang mendukung kinerja individu dan keefektifan organisasi. Sebagai perilaku di luar peran yang harus dimainkan, sesungguhnya OCB tidak dapat dipisahkan dari perilaku kerja yang dituntut dalam pekerjaannya atau yang sesuai dengan peran yang dimainkannya. Organisasi bisa mengaplikasikan hal tersebut dalam penilaian kinerja karyawan mengingat perilaku di luar peran juga menjadi standar yang harus dipenuhi karyawan untuk menilai kinerja karyawan. Selain itu, organisasi dapat mendorong agar karyawan positif, misalnya membantu karyawan lain dan saling mendukung dalam tim.Karena ada karyawan yang dengan suka rela membantu teman lain, tetapi ada juga pribadi yang harus didorong terlebih dulu oleh organisasi. Dalam seleksi karyawan pun,organisasi bisa memilih karyawan yang mempunyai kepribadian positif. Lebih penting dari semua itu, 
organisasi dapat membentuk lingkungan yang kondusif yang dapat mendorong OCB dalam berbagai kegiatan.

Menurut Rivai (20005) "kinerja adalah hasil kerja yang dapat dicapai oleh seseorang atau kelompok dalam suatu perusahaan sesuai dengan wewenang dan tanggung jawab masing-masing dalam upaya pencapaian tujuan perusahaan secara legal, tidak melanggar hukum dan tidak bertentangan dengan moral atau etika".

Selanjutnya menurut

Mangkunegara (2007: 56) "kinerja adalah hasil kerja yang dicapai secara kualitas dan kuantitas oleh seorang karyawan dalam melaksanakan tugasnya sesuai dengan tanggung jawab yang diberikan kepadanya".

Dari pengertian prestasi kerja diatas, maka dapat disimpulkan bahwa pada hakikatnya prestasi kerja merupakan prestasi yang dicapai seseorang dalam melaksanakan tugasnya atau pekerjaannya sesuai dengan standar dan kriteria yang ditetapkan untuk pekerjaan itu.

Tujuan penilaian prestasi kerja adalah untuk memperbaiki atau meningkatkan prestasi organisasi melalui peningkatan prestasi dari sumber daya manusia organisasi. Menurut Sunyoto dalam Mangkunegara (2007: 43), secara lebih spesifik tujuan dari penilaian prestasi kerja adalah sebagai berikut :

a. Meningkatkan rasa saling pengertian antar karyawan tentang persyaratan prestasi.

b. Mencatat dan mengakui hasil kerja seorang karyawan, sehingga mereka termotivasi untuk berbuat yang lebih baik, atau sekurang-kurangnya berprestasi sama dengan prestasi yang terdahulu.

c. Memberikan peluang kepada karyawan untuk mendiskusikan keinginan dan aspirasinya dan meningkatkan kepedulian terhadap karir atau terhadap pekerjaan yang diemban sekarang.

d. Mendefinisikan atau merumuskan kembali sasaran masa depan sehingga karyawan termotivasi untuk berprestasi sesuai dengan potensinya.

e. Memeriksa rencana pelaksanaan dan pengembangan yang sesuai dengan kebutuhan pelatihan, khususnya rencana diklat, dan kemudian menyetujui rencana itu jika tidak ada hal-hal yang perlu diubah.

\section{Faktor-faktor Penilaian Kinerja}

Simamora (2001: 42) menyatakan bahwa "ada 3 (tiga) hal yang dimasukkan dalam penilaian prestasi kerja, yaitu : tingkat kedisiplinan, tingkat kemampuan, serta perilaku-perilaku inovatif dan spontan". Sedangkan Werther dan Davis (2001: 217) menyatakan penilaian prestasi kerja yang dilakukan dapat lebih dipercaya dan obyektif, perlu dirumuskan batasan atau faktor-faktor penilaian prestasi kerja sebagai berikut :

1. Performance, yaitu keberhasilan atau pencapaian tugas dalam jabatan.

2. Competency, yaitu kemahiran atau penguasaan pekerjaan sesuai dengan tuntutan jabatan.

3. Job Behavior, yaitu kesediaan untuk menampilkan perilaku atau mentalitas yang mendukung peningkatan prestasi kerja.

4. Potency, yaitu kemampuan pribadi yang dapat dikembangkan.

\section{Hipotesis}

Berdasarkan rumusan masalah dan kerangka pemikiran, maka dapat dikemukakan hipotesis penelitian, bahwa "Diduga Organizational citizenship behavior (OCB) secara simultan berpengaruh terhadap kinerja karyawan PT. Inti Kharisma Mandiri Riau Pekanbaru".

\section{Metode Penelitian}

\section{a. Variabel Penelitian}

Penelitian ini terdiri dari tiga variabel bebas (independent variable) yang terdiri atas kepatuhan (obedience), loyalitas (loyality) dan partisipasi. Sedangkan variabel terikat (dependent variabel) yaitu kinerja karyawan. 


\section{b. Lokasi Penelitian}

Penelitian ini dilakukan di PT. Inti Kharisma Mandiri Riau Pekanbaru yang beralamat di Jalan Tuanku Tambusai No.7 Pekanbaru.

\section{c. Populasi dan Sampel}

Populasi penelitian ini adalah seluruh karyawan bidang redaksi PT. Inti Kharisma Mandiri Riau Pekanbaru yang berjumlah 100 orang. Penentuan jumlah sampel dalam penelitian ini menggunakan rumus Slovin (Umar, 2001: 42) yang dituliskan sebagai berikut :

$$
\mathrm{n}=\frac{N}{1+N(e)^{2}}
$$

dimana :

$\mathrm{n}=$ jumlah sampel

$\mathrm{N}=$ Jumlah populasi

(error term)

$\mathrm{e}=$ tingkat kelonggaran kesalahan

Populasi (N) sebanyak 100 orang karyawan PT. Inti Kharisma Mandiri Riau dengan asumsi tingkat kesalahan (e) sebesar $10 \%$, maka perhitungan jumlah sampel adalah sebagai berikut :

$$
\mathrm{n}=\frac{100}{1+100^{\prime \prime}\left(1_{1}^{z}\right.}=50 \text { orang }
$$

\section{d. Metode Pengumpulan Data}

Metode pengumpulan data yang digunakan dalam penelitian ini adalah :

1. Wawancara (interview) yang dilakukan kepada pimpinan Divisi Sumber Daya Manusia PT. Inti Kharisma Mandiri Riau Pekanbaru atau pihak-pihak lain yang ditunjuk oleh perusahaan untuk memberikan informasi dan keterangan yang dibutuhkan dalam penelitian ini.

2. Daftar pertanyaan (questionairre) yang diberikan kepada karyawan bidang redaksi PT. Inti Kharisma Mandiri Riau Pekanbaru yang menjadi responden dalam penelitian ini.

\section{Hasil Penelitian}

1. Analisis Data

Analisis Regresi Linear Berganda dengan menggunakan Teknik Tranformasi yang paling sederhana dengan menggunakan Method of Successive Interval (MSI) yang berguna mentranformasikan data ordinal menjadi data interval yang mampu menguji besarnya sumbangan (kontribusi) yang ditunjukkan oleh koefisienl antar variabel $\mathrm{X} 1, \mathrm{X} 2$ dan $\mathrm{Y}$ agar tidak bias.

\section{Uji Validitas}

Pengolahan validitas instrumen Regresi bertahap yang merupakan dasar dari perhitungan koefisien beta kemudian dibantu dengan software pengolahan data Statistical Package for Social Sciencec (SPSS) 17.0. Butir-butir yang sudah valid berdasarkan MSI tergambar dalam terjemahan statistik dalam tabel berikut:

\section{Uji Normalitas}

Uji normalitas bertujuan untuk menguji apakah dalam model regresi, variabel pengganggu atau residual memiliki distribusi normal. Dalam uji t dan uji $\mathrm{F}$ diasumsikan bahwa nilai residual mengikuti distribusi normal.

Untuk melihat normalitas residual dilakukan dengan melihat normal probability plot yang membandingkan distribusi kumulatif dari distribusi normal. Distribusi normal akan membentuk satu garis lurus diagonal. Jika distribusi data residual normal, maka garis yang menggambarkan data sesungguhnya akan mengikuti garis diagonalnya. Selain menggunakan grafik, untuk mengetahui apakah data berdistribusi normal atau mendekati normal bisa juga dilakukan dengan menggunakan uji statistik non parametrik Kolmogorov-Smirmov yaitu dengan menggunakan tabel KolmogorovSmirmov Test (Ghozali, 2005: 104).

\section{Uji Multikolinieritas}

Uji multikolinieritas bertujuan untuk menguji apakah model regresi ditemukan adanya korelasi antar variabel bebas (independen). Model regresi yang baik seharusnya tidak terjadi korelasi antar variabel independen. Menurut Ghozali (2005: 105) jika variabel independen saling berkorelasi maka maka variabel ini tidak ortogonal. Variabel ortogonal adalah variabel 
independen yang nilai korelasi antar sesama variabel independen sama dengan nol. Untuk mendeteksi ada tidaknya multikolinieritas didalam model regresi dapat dilihat dari nilai tolerance dan Variance Inflation Factor (VIF), jika nilai tolerance $<0,10$ atau nilai VIF $>10$ berarti terdapat multikolinieritas.

\section{Uji Heteroskedastisitas}

Uji heteroskedastisitas bertujuan menguji apakah dalam model regresi terjadi ketidaksamaan variance dari residual satu pengamatan ke pengamatan yang lain. Jika variance dari residual satu pengamatan ke pengamatan yang lain tetap maka disebut homokedastisitas dan jika berbeda disebut heterokedastisitas.Gejala heterokedastisitas dapat diuji dengan menggunakan uji Glejser yaitu dengan meregres nilai absolute residual terhadap variabel independen (Ghozali, 2005: 105). Heteroskedastisitas dengan uji Glejser tidak terjadi apabila tidak satupun variabel independen signifikan secara statistik mempengaruhi variabel independen nilai absolut Ut (AbsUt).

\section{Pembahasan}

\section{Model $Y=a+b 1 X 1+b 2 X 2+b 3 X 3+e$}

Pengujian hipotesis yang dikemukakan dilakukan dengan pembuktian secara total/simultan dari masing-masing variabel bebas.

\section{a. Pengujian Hipotesis Secara Total/Simultan}

Pembuktian hipotesis secara total digunakan untuk melihat pengaruh variabel bebas secara bersama-sama yaitu kepatuhan, loyalitas dan partisipasi berpengaruh terhadap Kinerja. Berdasarkan hasil perhitungan, maka diperoleh data-data perhitungan sebagai berikut:
Tabel

Hasil Uji Koefisien Regresi

\begin{tabular}{|l|c|r|l|}
\hline \multirow{2}{*}{} & \multicolumn{2}{|c|}{$\begin{array}{l}\text { Unstandardized } \\
\text { Coefficients }\end{array}$} & $\begin{array}{l}\text { Standardized } \\
\text { Coefficients }\end{array}$ \\
\cline { 2 - 4 } & $\mathrm{B}$ & $\begin{array}{c}\text { Std. } \\
\text { Error }\end{array}$ & Beta \\
\hline (Constant) & .490 & .843 & \\
\hline Kepatuhan & .124 & .049 & .197 \\
\hline Loyalitas & .304 & .051 & .561 \\
\hline Partisipasi & .412 & .153 & .258 \\
\hline
\end{tabular}

Sumber: Hasil Penelitian, 2014 (Data Diolah)

Dari tabel tersebut diperoleh persamaan regresi linier berganda sebagai berikut:

$\hat{Y}=0.490+0.124 X_{1}+0.304 X_{2}+0.412 X_{3}+e$

\section{b. Koofisien Determinasi ( $R$-Square)}

Nilai koefisien determinasi $\left(\mathrm{R}^{2}\right)$ dipergunakan untuk mengetahui pengaruh variabel bebas yang terdiri atas kepatuhan $\left(\mathrm{X}_{1}\right)$, loyalitas $\left(\mathrm{X}_{2}\right)$ dan partisipasi $\left(\mathrm{X}_{3}\right)$ terhadap prestasi kerja (Y) karyawan PT. Inti Kharisma Mandiri Riau Pekanbaru.

Tabel Hasil Uji Determinasi

\begin{tabular}{|c|c|c|c|}
\hline $\mathrm{R}$ & $\begin{array}{c}\mathrm{R} \\
\text { Square }\end{array}$ & $\begin{array}{c}\text { Adjusted } \\
\text { R Square }\end{array}$ & $\begin{array}{c}\text { Std. } \\
\text { Error of } \\
\text { the } \\
\text { Estimate }\end{array}$ \\
\hline $.918(\mathrm{a})$ & .843 & .833 & .65738 \\
\hline \multicolumn{2}{|c|}{ Sumber: Hasil Penelitian, 2014(Data Diolah) }
\end{tabular}

\section{c. Uji Simultan}

Hasil pengujian hipotesis secara simultan (serempak) dapat dilihat pada tabel IV.3 berikut:

Tabel Hasil Uji F

\begin{tabular}{|c|c|c|c|c|l|}
\hline & $\begin{array}{c}\text { Sum of } \\
\text { Squares }\end{array}$ & Df & $\begin{array}{c}\text { Mean } \\
\text { Squar } \\
\text { e }\end{array}$ & F & Sig. \\
\hline $\begin{array}{c}\text { Regres } \\
\text { sion }\end{array}$ & 107.101 & 3 & $\begin{array}{c}35.70 \\
0\end{array}$ & $\begin{array}{c}82 . \\
612\end{array}$ & $\begin{array}{l}.000 \\
\text { (a) }\end{array}$ \\
\hline $\begin{array}{c}\text { Residu } \\
\text { al }\end{array}$ & 19.879 & 46 & .432 & & \\
\hline Total & 126.980 & 49 & & & \\
\hline
\end{tabular}

Sumber: Hasil Penelitian, 2014 (Data Diolah)

Berdasarkan Tabel IV.3 diperoleh bahwa nilai $F_{\text {hitung }}(82,612)$ lebih besar dibandingkan dengan nilai $\mathrm{F}_{\text {tabel }}(2,81)$, dan sig. $\alpha\left(0,000^{\mathrm{a}}\right)$ lebih kecil dari alpha 5\% $(0,05)$. Hal ini mengindikasikan bahwa hasil 
penelitian menolak $\mathrm{H}_{0}$ dan menerima $\mathrm{H}_{\mathrm{a}}$. Dengan demikian secara serempak kepatuha, loyalitas dan partisipasi berpengaruh sangat signifikan terhadap kinerja karyawan PT. Inti Kharisma Mandiri Riau Pekanbaru.

\section{d. Uji Parsial}

Hasil pengujian hipotesis secara parsial dapat dilihat pada tabel IV.4 berikut:

Tabel Hasil Uji Parsial

\begin{tabular}{|c|c|c|}
\hline & $\mathrm{T}$ & Sig. \\
\hline (Constant) & .581 & .564 \\
\hline Kepatuhan & 2.515 & .015 \\
\hline Loyalitas & 5.983 & .000 \\
\hline Partisipasi & 2.691 & .010 \\
\hline
\end{tabular}

Berdasarkan Tabel IV.4 diperoleh hasil sebagai berikut:

1. Nilai $t_{\text {hitung }}$ untuk variabel kepatuhan $(2,515)$ lebih besar dibandingkan dengan nilai $t_{\text {tabel }}$ $(2,01)$, atau nilai sig. $\mathrm{t}$ untuk variabel kepatuhan $(0,015)$ lebih kecil dari alpha $(0,025)$. Ini berarti kepatuhan berpengaruh secara parsial terhadap kinerja karyawan PT. Inti Kharisma Mandiri Riau Pekanbaru.

2. Nilai $t_{\text {hitung }}$ untuk variabel loyalitas $(5,983)$ lebih besar dibandingkan dengan nilai $t_{\text {tabel }}(2,01)$, atau nilai sig. $t$ untuk variabel loyalitas $(0,000)$ lebih kecil dari alpha $(0,025)$. Ini berarti loyalitas berpengaruh terhadap kinerja karyawan PT. Inti Kharisma Mandiri Riau Pekanbaru.

3. Nilai $t_{\text {hitung }}$ untuk variabel partisipasi $(2,691)$ lebih besar dibandingkan dengan nilai $t_{\text {tabel }}(2,01)$, atau nilai sig $t$ untuk variabel partisipasi $(0,010)$ lebih kecil dari alpha $(0,025)$. Ini berarti partisipasi berpengaruh terhadap kinerja karyawan PT. Inti Kharisma Mandiri Riau Pekanbaru.

\section{Kesimpulan}

1. Secara serempak, kepatuhan (obedience), loyalitas dan partisipasi berpengaruh terhadap kinerja kayawan PT. Inti Kharisma Mandiri Riau Pekanbaru dengan tingkat pengaruh yang sangat signifikan.
2. Secara parsial loyalitas berpengaruh lebih dominan daripada kepatuhan dan partisipasi Hal ini berarti bahwa variabel loyalitas lebih menentukan dalam meningkatkan kinerja karyawan.

\section{Saran}

1. Perusahaan hendaknya memperhatikan dan memberikan penghargaan kepada setiap karyawan yang memiliki perilaku $O C B$ yang lebih menonjol dengan demikian karyawan lain akan termotivasi untuk melakukan hal yang sama.

2. Perusahaan dapat mendorong karyawan berlaku positif misalnya membantu karyawan lain dengan saling mendukung dalam tim. Selain itu perusahaan perlu membentuk lingkungan kondusif yang dapat mendorong $O C B$ dalam berbagai kegiatan.

\section{DAFTAR PUSTAKA}

Ariani, D.W. (2008). Perilaku Kewargaan Organisasional. http://www.ugm.ac.id /index.

Appelbaum, S., et al. (2004). "Organizational Citizenship Behavior: a Case Study of Culture, Leadership and Trust" Management Decision, Vol. 42 No. 1, 2004 pp.13-40

Bienstock, C.C., DeMoranville, C.W., dan Smith, R.K. ( 2003). "Organizational

Bogler, R., dan Somech, A. (2005). "Organizational Citizenship Behavior in School. How Does it Relate to Participation in Decision Making?". Journal of Educational Administration, Vol. 43 No. 5, 2005 pp. 420-438 10Citizenship Behavior and Service Quality". Journal of Services Marketing, Vol17 No. 4, 2003 pp. 357- 378

Bolino, M.C., Turnley, W.H., dan Bloodgood, J.M. ( 2002). "Citizenship Behavior and the Creation of Social 
Capital in Organization". Academy of Management Journal, Vol. 7, No. 4, 2002 pp. $502-522$

Cascio, Wayne F., 2000. Managin Human Resources : Productivity, Quality of Work Life, Profit, Mc Graw-Hill, Inc., Singapore.

Chang, Richard Y., 2001. Sukses Melalui Kerjasama Tim, Cetakan Kedua, Penerjemah: Ramelan, PPM: Jakarta.

Djarwanto. 1996. Mengenal Beberapa Uji

Statistik Dalam Penelitian. Liberty: Yogyakarta.

Ghozali, Imam. 2006. Aplikasi Analisis Multivariate dengan Program SPSS. Badan Penerbit Universitas Diponegoro: Semarang.

Korte, Russel F., Wong, Chermack, Thomas J., 2006. Changing Organizational
Culture With Scenario Planning. University of Minnesota.

Kreitner, Robert. 2000. Management. Houghton Mifflin Company.

Mangkunegara, A.A. Anwar Prabu. 2007. Evaluasi Kinerja SDM. Refika Aditama: Bandung.

Mangkuprawira, Tb. Sjafri. 2004. Manajemen Sumber Daya Manusia Strategik, Cetakan Ketiga. Ghalia: Jakarta.

Nawawi, H. Hadari. 2000. Manajemen Sumber Daya Manusia Untuk Bisnis Yang Kompetitif. Gajah Mada University Press: Yogyakarta. 